\title{
C aenorhabditis elegans Akt/PKB transoluces insulin receptor-like signals from AGE-1 PI3 kinase to the DAF-16 transcription factor
}

\author{
Suzanne Paradis and Gary Ruvkun ${ }^{1}$ \\ Department of Molecular Biology, Massachusetts General Hospital (MGH) and Department of Genetics, Harvard M edical \\ School, Boston, Massachusetts 02114 USA
}

\begin{abstract}
A neurosecretory pathway regulates a reversible developmental arrest and metabolic shift at the C aenorhabditis elegans dauer larval stage. Defects in an insulin-like signaling pathway cause arrest at the dauer stage. We show here that two C. elegans Akt/PKB homologs, akt-1 and akt-2, transduce insulin receptor-like signals that inhibit dauer arrest and that AKT-1 and AKT-2 signaling are indispensable for insulin receptor-like signaling in C. elegans. A loss-of-function mutation in the Fork head transcription factor DAF-16 relieves the requirement for Akt/PKB signaling which indicates that AKT-1 and AKT-2 function primarily to antagonize DAF-16. This is the first evidence that the major target of Akt/PKB signaling is a transcription factor. An activating mutation in akt-1, revealed by a genetic screen, as well as increased dosage of wild-type akt-1 relieves the requirement for signaling from AGE-1 PI3K, which acts downstream of the DAF-2 insulin/IGF-1 receptor homolog. This demonstrates that Akt/PKB activity is not necessarily dependent on AGE-1 PI3K activity. akt-1 and akt-2 are expressed in overlapping pattems in the nervous system and in tissues that are remodeled during dauer formation.
\end{abstract}

[Key Words: Insulin signaling; dauer; Fork head transcription factor; life span]

Received May 14, 1998; revised version accepted June 25, 1998.

An insulin receptor-like signaling pathway regulates Caenorhabditis elegans metabolism, development, and longevity (Kimura et al. 1997). This insulin receptor pathway is required for reproductive growth and normal metabolism. Mutations in the insulin/IGF-I receptor homolog daf-2 (Kimura et al. 1997) or in the phosphoinositide-3-OH kinase (PI3K) homolog age-1 (Morris et al. 1996) cause ani mals to arrest as dauers, shift metabolism to fat storage, and live longer (Kenyon et al. 1993; Larsen et al. 1995; Kimura et al. 1997). This regulation of C. elegans metabolism is similar to the physiological role of mammalian insulin in metabolic regulation. Insulin controls glucose homeostasis by changing the activity of key metabolic regulators, such as glucose transporters and metabolic enzymes (A vruch 1998). Mutations in the Fork head transcription factor DAF-16 completely suppress the dauer arrest, metabolic shift, and Iongevity phenotypes of daf-2 and age-1 mutants (Kenyon et al. 1993; Gottlieb and Ruvkun 1994; Larsen et al. 1995; Lin et al. 1997; Ogg et al. 1997), indicating that DAF-16 is a negatively regulated downstream target of $C$. el egans insulin receptor-like signaling. Mammalian homologs of
DAF-16 may similarly be regulated by insulin receptor signaling to mediate the transcriptional effects of insul in (Ogg et al . 1997). Molecules that couple the DAF-2 insulin receptor-like protein and AGE-1 PI3K to the DAF-16 transcription factor have not been identified by previous extensive genetic screens.

Activation of the mammalian insulin receptor tyrosine kinase in response to insulin binding has been shown biochemically to affect multiple downstream targets that regulate cellular responses to insulin. Some of the major downstream effectors of insulin receptor activation include Ras and PI3K; these molecules have outputs to diverse biological processes, such as cell growth, gene expression, glycogen synthesis, protein synthesis, and glucose transport in response to insulin receptor activation (Kahn 1994).

Activated PI3K generates 3-phosphoinositides, such as phosphatidylinositol-3,4-bi sphosphate (Ptdlns-3,4-P2) and Ptdlns-3,4,5-P3 (Kapeller and Cantley 1994). Ptdlns3,4-P2 and Ptdlns-3,4,5-P3 are thought to act as second messengers because their levels rise rapidly in response to growth factor signaling (Toker and Cantley 1997). PI3K has been implicated in a variety of cellular responses to growth factor signaling such as mitogenesis, receptor trafficking, regulation of the actin cytoskel eton, and cell survival (Carpenter and Cantley 1996). A few 
downstream effectors of PI3K signaling have been identified biochemically and shown to bind to the 3-phosphoinositides generated by PI3K. These include the serine/threonine kinase Akt/PKB (al so known as RAC) and other pleckstrin homology $(\mathrm{PH})$ domain containing proteins, certain PKC isoforms, and $\mathrm{SH} 2$ domain-containing proteins (Toker and Cantley 1997).

Activation of Akt/PKB is dependent on PI3K activation-Ptdlns-3,4-P2 and/or Ptdlns-3,4,5-P3 bind to the amino-terminal PH domain of Akt/PKB and activate the kinase (Franke et al. 1997; Frech et al . 1997; Klippel et al. 1997). Phospholipid binding presumably causes a conformational and/or localization change that makes Akt/ PKB more accessible to phosphorylation events that are necessary for activation (Alessi et al. 1997; Stokoe et al. 1997). Akt/PKB has been implicated in cellular responses to insulin signaling, such as gl ucose transporter translocation and expression and glycogen synthesis (Cross et al. 1995; Kohn et al. 1996). Akt/PKB has also been shown to have anti-apoptotic activities in response to signal ing by various growth factor receptors including insulin and IGF-1 (Dudek et al. 1997; Kauffmann-Zeh et al. 1997; Kulik et al. 1997).

Although biochemical studies suggest that mammaIian Akt/PKB transduces signals from PI3Ks associated with receptor tyrosine kinases such as the insulin receptor to downstream effectors, this has not been demonstrated by genetic analysis of signaling pathways in whole organisms. Such an analysis could reveal the key signaling inputs to Akt/PKB as well as major targets of Akt/PKB. We report the identification of two $C$. el egans Akt/PKB homologs, akt-1 and akt-2. We establish the action of AKT-1 and AKT-2 in the DAF-2 insulin receptor-like signaling pathway by the isolation of an activating akt-1 mutation in a screen for suppressors of an AGE-1 PI3K null allele and by genetic analysis of akt-1 and akt- 2 inactivation and overexpression. We find that an activating mutation in akt-1 or increased dosage of akt-1( + ) can bypass the normal requirement for AGE-1 PI3K signaling but still partially depends on DAF-2 signaling, showing that akt- 1 is the major output of PI3K signaling but not the only output of the DAF-2 insulinlike receptor. We show that inactivation of $C$. elegans Akt/PKB signaling causes a dauer constitutive phenotype; we therefore conclude that Akt/PKB signaling is necessary for reproductive growth and metabolism. N ull mutations in the DAF-16 Fork head transcription factor reli eve the requi rement for $A k t / P K B$ signal ing to repress dauer formation, indicating that DAF-16 is a major downstream target of Akt/PKB signaling.

\section{Results}

akt-1(mgl44) is an activating mutation in a C. elegans Akt/PKB homolog that relieves the requirement for AGE-1 PI3K signaling

The almost complete genome sequence of $C$. elegans (Wilson et al. 1994) (A. Coul son, pers. comm.) reveals the presence of two Akt/PKB homologs that we named akt-1 and akt-2 (Fig. 1). An activating mutation (mg144) in akt-1 was identified in a genetic screen for mutations that suppress the dauer arrest phenotype of the age1 (mg44) null mutant (Morris et al. 1996). This screen was designed to isolate reduction of function mutations in molecules negatively regulated by PI3K signaling, or gain of function mutations in molecules positively regulated by PI3K signaling. Ten independent suppressor mutations emerged from a screen of $\sim 3800$ hapl oid genomes. In addition to the dominant-activating akt-1 mutation, two alleles of daf-16, a previously known negatively regulated target (Gottli eb and Ruvkun 1994; Larsen et al. 1995), were isolated [daf-16(mg87) (Ogg et al . 1997) and one other mutation that maps to the daf-16 interval between lin-11 and unc-75 and is presumed to be allelic]. This suggests that the screen reveals genes that act in this insulin-like signaling pathway. Another dominant mutation, mg142, which suppresses multiple age-1 alleles, and six mutations that vary in their ability to suppress multiple age- 1 alleles were also isolated in the screen.

The mg144 mutation suppresses the three age-1 alleles tested (Table 1; data not shown), including two classes of nonsense mutations (Morris et al. 1996) and one missense mutation in a conserved residue of PI3K. mg144 is completely dominant for suppression of the dauer constitutive phenotype of age-1(mg44) $[75.1 \%$ of the progeny of age-1(mg44); mg144/ + animals develop as nondauers, $24.9 \%$ arrest at the dauer stage, $n=774]$. On its own, mgl44 does not have any obvious phentoypes (Table 1); the strain arrests as dauers on starved plates and on plates treated with pheromone, it moves normally, and has a normal vulva and brood size. Therefore mg144 does not activate the AGE-1 PI3K signaling pathway to the point that normal dauer arrest is affected but does activate the pathway sufficiently to alleviate the requirement for $A G E-1$ PI3K outputs.

Using suppression of the dauer constitutive phenotype of age-1(mg44), mgl44 was mapped to a region on chromosome $V$ within 1.3 map units (m.u.) of the polymorphic ST S marker bP1 (Fig. 1A ). This 1.3-m.u. regi on contains the $C$. elegans Akt/PKB homolog akt-1 (Fig. 1A). Because an activating mutation in Akt/PKB is a good candidate to be a suppressor of an age-1 PI3K null mutant, we determined the akt-1 DNA sequence in the mgl44 strain by PCR amplification and direct sequencing. The akt- 1 gene in the mgl44 mutant strain bears an Ala183T hr substitution (Fig. 1D). akt-1 is differentially spliced within the conserved kinase domain to generate the akt-1a and akt-1b isoforms with distinct kinase domain subregions IV, V, and VI (Hanks and Hunter 1995) (Fig. 1A,D) (92\% identical , 238/258 amino acids over the entire kinase domain; 69\% identical, 44/64 amino acids in the differentially spliced region). akt- 1 a is $58 \%$ identical to human Akt/PKB $\alpha$ overall (Fig. 1C,D). akt-1 has a pleckstrin homology domain, kinase domain, and the two phosphorylation sites necessary for mammalian Akt/PKB activation (Alessi et al. 1996a), which are the hallmarks of the Akt/PKB family (Fig. 1D). The next most closely related mammalian kinase is rat $\mathrm{PKC} \beta 1$, 
Figure 1. akt-1 and akt-2 encode Akt/PKB serine/threonine kinases. (A, top) Genetic and physical map of the akt-1 region; akt-1 is contained on cosmid C12D8. (Bottom) Exon/intron structure of akt-1. Coding regions are solid boxes, noncoding regions are open boxes, and introns are lines. The pleckstrin homology domain is indicated by hatched boxes (Musacchio et al. 1993), the kinase domain (Hanks and Hunter 1995) is indicated in gray. (B, top) Genetic and physical map of the akt-2 region; akt- 2 is contained on cosmid R03E1. (Bottom) Exon/intron stucture of akt-2. All symbols are as in A. (C) Dendogram of Akt/PKB and PKC protein kinase families. PILEUP (GCG) was used to align the entire coding sequences of the indicated proteins. (Ce) C. el egans proteins; (r) rat; (h) human; (m) mouse; (b) bovine; (D) D. melanogaster. The GenBank accession numbers for the proteins used in the PILEUP are contained in parentheses: CePKC2a(U 82935), rPKC $\beta 1$ (M 19007), hAkt/ PKB $\alpha(M$ 63167), mAkt/PKB(M 94335), bAkt/ $\mathrm{PKB}(X 61036)$, hAkt/PKBß2(M 95936), rAkt/ PKBy(D 49836), and Dakt1 (Z26242). The accession numbers for the proteins reported in the paper are contained in parentheses: AKT-la (AF072379), AKT-1b (AF072380), and AKT-2 (AF072381). As an outgroup, rPKC $\beta 1$ (the closest non-Akt/PKB homolog to both akt-la and hAkt/PKB $\alpha$ ) and CePKC2a (the closest $C$. el egans homolog to rPKC $\beta 1$ ) were included in the PILEUP. The Akt/PKB homologs described in this report are indicated by the gray box. (D) AKT-1a, AKT-1b, AKT-2, and human Akt/PKB $\alpha$ (M 63167) were aligned using PILEUP. Identical residues are indicated by dots; gaps introduced to align the sequence are indicated by dashes. The pleckstrin homology domain (Musacchio et al. 1993) is indicated by the amino-terminal shaded areas; the kinase domain (Hanks and Hunter 1995) is indicated by the carboxy-terminal shaded areas. The mgl44 Ala-183-Thr substitution is indicated as a T above the AKT-1a sequence (SEAAKRD). The AKT-1 and AKT-2 phosphorylation sites that correspond to the hAkt/PKB $\alpha$ Thr-308 and Ser-473 phosphorylation sites (Alessi et al. 1996a) are indicated as dots above the amino acid residue that is phosphorylated.

which is $38 \%$ identical to akt-la overall. The akt1 (mg144) mutation is present in both splice forms of akt- 1 and is located in a region of the protein that links the amino-terminal pleckstrin homology domain to the carboxy-terminal kinase domain. This mutation is in a region that is not conserved between $C$. elegans and mammalian Akt/PKB and may reveal a negative regulatory region on akt-1 because the mg144 allele is an activating mutation (see below).

To confirm that the mgl44 suppression of age-1 that is genetically linked to akt- 1 is due to a mutation in akt- 1 , we used a reverse genetic assay termed RN A interference (RN Ai) (Fire et al. 1998; Rochel eau et al. 1997; Zhang et al. 1997) to decrease akt-1 gene activity in an age 1(mg44); akt-1(mgl44) strain. If a mutation in akt-1 is responsible for the suppression of age-1 observed in this strain, RNAi of akt-1 in this strain should revert the suppression phenotype and result in a dauer constitutive phenotype. This experiment is conceptually similar to the classic genetic arguments that show that a cis-acting loss-of-function mutation can revert a gain-of-function mutation in the same gene. Inhibition of akt-1 activity in an age 1 (mg44); akt-1(mg144) strain reverts the akt1 (mgl44) suppression phenotype (Table 2). Inhibition of akt-1 activity in wild type does not induce dauer arrest (Table 2). Therefore we conclude that the mgl44-activating mutation is a lesion in the akt-1 locus.

The C. elegans Akt/PKB homolog akt-2 functions redundantly with akt-1 to repress dauer formation and negatively regulate the DAF-16 transcription factor The C. elegans Akt/PKB homol og akt-2 (Fig. 1B) is 55\% 
Table 1. Effects of akt-1(mg144) on dauer formation

\begin{tabular}{|c|c|c|c|c|c|c|}
\hline \multirow[b]{2}{*}{ Genotype of parent } & \multicolumn{6}{|c|}{ Phenotype of progeny at $25^{\circ} \mathrm{C}(\%)$} \\
\hline & $\begin{array}{l}\text { L4 larvae } \\
\text { and adult }\end{array}$ & dauer & $\begin{array}{c}\text { partial } \\
\text { dauer }\end{array}$ & $\begin{array}{l}\text { dead } \\
\text { eggs }\end{array}$ & other & $\mathrm{N}^{\mathrm{a}}$ \\
\hline Wild type & 100 & 0 & 0 & 0 & N.D. & 403 \\
\hline akt-1(mgl44) & 98.4 & 0 & 0 & 1.6 & N.D. & 314 \\
\hline sqt-1(sc13) age-1(mg44) b & 0 & 82.2 & 0 & 3.2 & $14.6^{c}$ & 185 \\
\hline sqt-1(sc13) age-1(mg44); akt-1(mg144) $)^{\mathrm{d}, \mathrm{e}}$ & 88.2 & 0 & 0 & 0.2 & $11.6^{\mathrm{f}}$ & 440 \\
\hline daf-16(m27); sqt-1(sc13) age-1(mg44) & 99.6 & 0 & 0 & 0.4 & N.D. & 269 \\
\hline unc- $4(\mathrm{el} 20)$ age- $1(\mathrm{~m} 333)^{\mathrm{b}}$ & 0 & 96.5 & 0 & 2.3 & 1.2 & 171 \\
\hline unc-4(el20) age-1(m333); akt-1(mg144) $)^{d, g}$ & 96.8 & 0 & 0 & 0 & 3.2 & 279 \\
\hline daf-2(el370) & 0 & 96.1 & 0 & 2.8 & 1.0 & 387 \\
\hline daf-2(e1370); akt-1(mgl44) ${ }^{\mathrm{h}}$ & 0 & 0 & 92.4 & 0 & 7.6 & 436 \\
\hline daf-16(m27); daf-2(e1370) & 99.8 & 0 & 0 & 0 & 0.2 & 499 \\
\hline
\end{tabular}

(N.D.) N ot determined.

See M aterials and methods for description of categories.

${ }^{a}(\mathrm{~N})$ Total number of animals scored. Numbers represent the summary of at least two trials of each genotype in at least two experiments performed on different days.

${ }^{\text {bT }}$ hese animals are the homozygous age-1 progeny of age-1/bal ancer hermaphrodites.

'N ine of nine animals scored became dauers by $97 \mathrm{hr}$ post-egg lay.

¿These animals are the homozygous age-1 progeny of homozygous age-1 hermaphrodites.

${ }^{\text {e}}$ Rescoring of the entire assay at $96 \mathrm{hr}$ post-egg lay: $90.5 \%$ of animals were gravid adults, $2.7 \%$ were sterile adults, $0.7 \%$ were dauers, and $6.1 \%$ were other $(\mathrm{N}=147)$; sqt-1(sc13) age-1(mg44) animals remained arrested at the dauer stage.

fBy $96 \mathrm{hr}$ post-egg lay, 5/28 animals scored became gravid adults, 11/28 became dauers or partial dauers, 10/28 became sterile adults, and $2 / 28$ remained as non-dauer-arrested larvae of various stages.

gRescoring of the entire assay at $72 \mathrm{hr}$ post-egg lay: $81.6 \%$ of animals were gravid adults, $17.8 \%$ were sterile adults, and $0.6 \%$ were other ( $\mathrm{N}=151)$; unc-4(e120) age-1(m333) animals remained arrested at the dauer stage.

${ }^{h}$ Rescoring of the entire assay at $96 \mathrm{hr}$ post-egg lay: $11.5 \%$ of animals were gravid adults, $66.3 \%$ were sterile adults, $6.9 \%$ were dauers, $13.9 \%$ were partial dauers, and $1.4 \%$ were other $(\mathrm{N}=418)$; daf-2(e1370) animals remained arrested at the dauer stage. In comparison, daf-16(m27); daf-2(e1370) animals formed $96.7 \%$ gravid adults, $2.9 \%$ sterile adults, and $0.4 \%$ other by $72 \mathrm{hr}$ post-egg lay ( $\mathrm{N}=486$ ).

identical to human $\mathrm{Akt} / \mathrm{PKB} \alpha$ overall and $35 \%$ identical to rat $\mathrm{PKC} \beta 1$ overall. akt-1 and akt-2 are more closely related to each other $(66 \%$ identity between akt-1a and akt-2 overall) than to any other Akt/PKB homolog (Fig. 1C). Interestingly, akt-2 only has the Thr308 phosphorylation site that is necessary for human Akt/PKB $\alpha$ activation by PDK1 (Alessi et al. 1997; Stokoe et al. 1997) but not the Ser473 phosphorylation site (Alessi et al. 1996a) (Fig. 1D) and yet clearly functions in the insulinlike signaling pathway (see below).

Reduction of both akt-1 and akt-2 activities revealed that they transduce insulin-like signals from the AGE-1 PI3K to the DAF-16 Fork head transcription factor. Inhibition of either akt-1 or akt-2 activity by RNAi does not cause dauer arrest (Table 2). Simultaneous inhibition of both akt- 1 and akt- 2 activities, however, causes nearly $100 \%$ arrest at the dauer stage (Table 2 ). We conclude that Akt/PKB signal ing from either akt- 1 or akt- 2 is sufficient for reproductive development. This result indicates that akt- 1 and akt- 2 can function redundantly in the control of $\mathrm{C}$. el egans reproductive development and metabolism and raises the possibility that various mammal ian A kt/PKB i soforms could function redundantly as well. Significantly, the constitutive dauer arrest induced by inhibition of both akt-1 and akt-2 is fully suppressed by a null mutation in daf-16 (Ogg et al. 1997) but is not suppressed by a null mutation in the Smad gene daf-3 (Patterson et al. 1997) (Table 2), which places akt-1 and akt-2 upstream of daf-16. Because a null mutation in daf-16 alleviates the need for C. elegans Akt/PKB signaling, the primary function of AKT-1 and AKT-2 is to antagonize DAF-16.

Genetic analysis of akt-1(mg144) and overexpression of akt- $1(+)$ and akt-1(mg144)

akt-1(mgl44) suppresses the dauer constitutive phenotype of three age 1 alleles (Table 1 ; data not shown). The suppression of these age- 1 alleles by akt-1(mgl44) is comparable with the suppression by daf-16(m27) (Table 1), a reduction of function allele (Lin et al. 1997). Because two of the age-1 alleles that are suppressed by akt1 (mg144) are nonsense al leles, these data strongly argue that akt- 1 acts downstream of age- 1 and that activation of AKT-1 can bypass the normal requirement of upstream AGE-1 PI3K signaling.

The normal requi rement of age-1 activity for reproductive devel opment is al so bypassed by increased gene dosage of wild-type akt-1. Transgenic age-1(mg44) animals carrying a 7.3-kb akt-1(+) genomic region as a transgene can grow reproductively rather than arrest at the dauer stage (T able 3 ). This rescue is dependent on a conserved lysine residue implicated in mammalian Akt/PKB kinase activity (Franke et al. 1995) [akt-1(KD); Table 3]. In a similar experiment with age-1(mg44) animal s carrying the same genomic region amplified from akt-1(mgl44), 
Table 2. Effects of akt-1(RNAi) and akt-2(RNAi) on dauer formation

\begin{tabular}{|c|c|c|c|c|c|c|c|}
\hline \multirow[b]{2}{*}{ Strain } & \multirow[b]{2}{*}{$\begin{array}{l}\text { dsRN A } \\
\text { injected }\end{array}$} & \multicolumn{6}{|c|}{ Phenotype of progeny at $25^{\circ} \mathrm{C}(\%)$} \\
\hline & & $\begin{array}{l}\text { L4 larvae } \\
\text { and adult }\end{array}$ & dauer & $\begin{array}{l}\text { partial } \\
\text { dauer }\end{array}$ & $\begin{array}{l}\text { dead } \\
\text { eggs }\end{array}$ & other & $\mathrm{N}^{\mathrm{a}}$ \\
\hline Wild type & uninjected & 99.8 & 0 & 0 & 0.2 & N.D. & 985 \\
\hline Wild type & akt-1 & 98.9 & 0 & 0 & 1.1 & N.D. & 542 \\
\hline Wild type & akt-2 & 97.3 & 0 & 0 & 2.7 & N.D. & 598 \\
\hline Wild type & akt-1 +akt-2 & 3.1 & $90.1^{\mathrm{b}}$ & 4.2 & 1.0 & 1.6 & 2123 \\
\hline daf-16(mgDf50) & uninjected & 99.0 & 0 & 0 & 1.0 & 0 & 968 \\
\hline daf-16(mgDf50) & akt-1 +akt-2 & 98.3 & 0 & 0 & 0.9 & 0.7 & 847 \\
\hline daf-3(mgDf90) & uninjected & 98.9 & 0 & 0 & 1.1 & N.D. & 925 \\
\hline daf-3(mgDf90) & akt-1 +akt-2 & 11.6 & 85.8 & 2.0 & 0.6 & N.D. & 1051 \\
\hline age-1(mg44); akt-1(mgl44)c & uninjected & 87.5 & 0.2 & 0 & 1.9 & $10.5^{d}$ & 536 \\
\hline age-1(mg44); akt-1(mg144)c & akt-1 & 5.4 & 70.6 & 9.0 & 6.0 & 9.0 & 299 \\
\hline age-1(mg44); akt-1(mgl44)c & akt-2 & 77.7 & 10.6 & 3.6 & 3.0 & 5.1 & 471 \\
\hline age-1(mg44) & uninjected & 0 & 82.2 & 0 & 3.2 & 14.6 & 185 \\
\hline
\end{tabular}

(N.D.) N ot determined.

See Materials and methods for description of categories.

${ }^{a}(\mathrm{~N})$ T otal number of animals scored. N umbers represent the summary of progeny scored from at least two seperate injections of each genotype in at least two experiments performed on different days.

bU nder the dissecting mi croscope animals were constricted and had a dark intestine like wild-type dauers. U sing N omarski optics, the dauers had dauer al ae (10/10), but the pharynx was not a dauer-remodeled pharynx (10/10) and, unlike in dauers, pharyngeal pumping was observed in some larvae (4/8). On a given plate, some dauers appeared smaller than wild-type dauers.

'The full genotype of this strain is sqt-1(sc13) age-1(mg44); him-8(e1489)/+; akt-1(mgl44).

'See Table 1 for discussion.

eThese data are from Table 1 and were added here for ease of comparison. The full genotype of this strain is sqt-1(sc13) age-1(mg44).

less transgenic animals arrested as dauers than age1 (mg44) animals carrying the akt- $1(+)$ transgene (Table 3), suggesting that the same 7.3-kb genomic region amplified from the akt-1(mgl44) strain may be a more potent suppressor of age-1(mg44) than the akt-1(+) transgene. This data, like the RNAi of akt-1(mgl44) using akt-1 RN A, maps mgl44 to the 7.3-kb region of akt-1 that includes the Ala-183-Thr substitution in AKT-1. AIthough multiple independent akt-1(mg144) transgenes are more potent suppressors of age-1(mg44) than akt-1(+) transgenes, which suggests that more akt-1 gene activity is generated by akt-1(mgl44), there is significant variation in the penetrance of suppression observed with different transgenes. In addition, even though akt-1(+) transgenes confer suppression of age-1(mg44) that is not observed with chromosomal akt-1(+), the penetrance of suppression of age-1(mg44) by either akt-1(t) or akt1 (mgl44) transgenes is less than from akt-1(mgl44)/+ heterozygotes or akt-1(mgl44) homozygotes (see above; Tables 1 and 3). This may be attributable to mosai cism of akt-1 gene expressi on from transgenic arrays or a saturation of akt-1 gene function by high gene dosage.

Inactivation of akt- 1 and akt- 2 by RN Ai causes dauer arrest, as do null mutations in age-1. Conversely, the dominant al lele akt-1(mgl44) or high gene dosage of akt$1(+)$ promotes reproductive growth even in an animal bearing an age 1 null mutation. Therefore akt-1(mgl44) has a similar genetic activity to increased akt-1(+) gene dosage and is an activating mutation, as opposed to a loss of function or dominant-negative mutation.

Because akt-1 and akt-2 function redundantly to repress dauer formation, we asked whether overexpression of akt-2(+) could al so bypass the normal requirement of
AGE-1 PI3K signaling. age-1(mg44) animal s carrying the akt-2(+) transgene arrested as dauers whereas age1 (mg44) animals carrying the akt- $1(+)$ transgene can bypass dauer (T able 3 ). Therefore either because of differences in the AKT-2 protein or differences in gene expression, high gene dosage of akt- 2 is not able to bypass the usual requirement for $A$ GE-1 PI3K signaling.

A mutation in daf-2 is suppressed more poorly by akt1 (mgl44) than by a reduction of function mutation in daf-16 (Table 1). The age-1 alleles suppressed by akt1 (mgl44) are null (Morris et al. 1996), whereas daf2(e1370) is a temperature-sensitive mutation in the kinase domain (Kimura et al. 1997). This daf-2 allele is suppressed completely by many daf-16 alleles, including null alleles (Gottlieb and Ruvkun 1994; Larsen et al. 1995; Ogg et al. 1997). This result, in comparison to the robust suppression of age-1 mutations by akt-1(mg144) (Table 1), suggests that AKT-1 is a major output of AGE-1 signaling and one of multiple outputs of DAF-2 signaling.

Overexpression of either akt-1(+) or akt-1(mgl44) can bypass the need for DAF-2 signaling, whereas overexpression of akt-2(+) or akt-1(KD) does not alleviate the need for DAF-2 signaling (Table 3$)$. akt-1(t) and akt1 (mgl44) transgenes, however, are more efficient suppressors of the dauer constitutive phenotype of age 1 (mg44) than of daf-2(e1370) (Table 3). This supports the model that AKT-1 is a primary output of AGE-1 signaling but is not the only output of DAF-2 signaling.

\section{Life-span regulation}

Reduction of zygotic age-1 activity increases C. elegans 
Table 3. Effects of akt-1 and akt-2 transgenes on dauer formation

\begin{tabular}{|c|c|c|c|c|c|}
\hline \multirow{2}{*}{$\begin{array}{l}\text { Dauer } \\
\text { constitutive } \\
\text { mutation }\end{array}$} & \multirow[b]{2}{*}{ Transgene } & \multicolumn{4}{|c|}{ Phenotype at $25^{\circ} \mathrm{C}(\%)$} \\
\hline & & $\begin{array}{l}\text { L4 larvae } \\
\text { and adult }\end{array}$ & dauer & other $^{\mathrm{a}}$ & $\mathrm{N}^{\mathrm{b}}$ \\
\hline Wild type ${ }^{c}$ & nor & 100 & 0 & 0 & 403 \\
\hline Wild & akt-1(t) & 97.6 & 0 & .4 & 454 \\
\hline Wild type & akt-1(mgl44) & 93.2 & 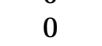 & $6.8^{d}$ & 414 \\
\hline Wild & akt-1(KD) $)^{\mathrm{e}}$ & 98.6 & 0 & 1.4 & 778 \\
\hline Wild type & akt-2(+) & 99.3 & 0 & 0.7 & 570 \\
\hline age-1(mg44) & none & 0 & 82.2 & 17.8 & 185 \\
\hline age-1(mg44) $)^{f}$ & akt-1(+) & 66.7 & 32.0 & 1.3 & 228 \\
\hline age-1(mg44) ${ }^{f}$ & akt-1(mgl44) & 88.3 & 7.6 & 4.1 & 341 \\
\hline age-1(mg44) & akt-1(KD) $)^{\mathrm{e}}$ & 0 & 100 & 0 & 58 \\
\hline age-1(mg44) ${ }^{f}$ & akt-2(+) & 0 & $100^{9}$ & 0 & 70 \\
\hline daf-2(e1370) $)^{c}$ & none & 0 & 96.1 & 3.9 & 387 \\
\hline daf-2(e1370) & akt-1(+) & 35.3 & $63.1^{\mathrm{h}}$ & 1.6 & 510 \\
\hline daf-2(e1370) & mg144) & 30.3 & 66.9 & 2.8 & 601 \\
\hline daf-2(e1370) & akt-1(KD) $)^{\mathrm{e}}$ & 0 & 92.5 & 7.5 & 375 \\
\hline daf-2(e1370) & akt-2(+) & 0 & 94.8 & 5.2 & 289 \\
\hline
\end{tabular}

See Materials and methods for description of categories.

aT his category includes dead eggs for the data imported from Table 1.

${ }^{b}(\mathrm{~N})$ T otal number of transgenic animals scored. N umbers represent the summary of at least two separate trials from two independent transgenic lines of each genotype.

'These data are from Table 1 and were added here for ease of comparison.

d72 hrs post-egg lay: Of 17 of these animals, 9 were L4 larvae or adults and 8 remained as non-dauer-arrested larvae of various stages.

eakt-1(KD) is a kinase-defective mutation that changes a conserved lysine in the ATP binding site to a methionine and has been shown to cause mammalian Akt/PKB to be a nonfunctional kinase (Franke et al. 1995).

${ }^{\mathrm{f}}$ The full genotype of this strain is sqt-1(sc13) age 1 (mg44).

$92.9 \%$ of these worms were partial dauers (see Materials and M ethods for description).

${ }^{\mathrm{h}} 7.4 \%$ of these worms were partial dauers (see Materials and Methods for description).

life span greater than twofold (Klass 1983; Larsen et al. 1995; M orris et al. 1996) (Table 4). Mutations in daf-16 suppress this life-span increase (Dorman et al. 1995; Larsen et al. 1995). akt-1(mgl44) does not suppress the age-1(mg44)-induced increase in life span (Table 4). Therefore akt-1(mgl44) bypasses the need for AGE-1 signaling in reproductive development but does not activate normal aging pathways. It is possible that akt1 (mg144) does not subserve all the functions of the wildtype akt-1. akt-2 or other as yet unidentified downstream effectors of age-1 may be the pertinent signaling molecules for life-span regulation.

\section{AKT-1/GFP and AKT-2/GFP are widely expressed}

The expression patterns of both akt-1 and akt-2 were examined in transgenic animals containing a translational fusion of each genomic locus to green fluorescent protein (GFP) (Chalfie et al. 1994). The GFP fusion proteins contain the entire genomic coding region from ei- ther akt-1 or akt-2, including $5^{\prime}$ upstream regulatory se quence, fused in frame at the carboxyl terminus to GFP. The AKT-1/GFP construct is sufficient to suppress the dauer constitutive phenotype of age-1(mg44), whereas the AKT-2/GFP construct is not (data not shown). This result is not unexpected because increased gene dosage of akt-2(+) does not suppress age-1(mg44), whereas increased gene dosage of akt- $1(+)$ does (Table 3). AKT-1/ GFP expression is first observed in late embryos and is maintai ned throughout the life of the animal. In postembryonic animals, AKT-1/GFP is expressed in the majority of head neurons including sensory neurons (Fig. 2A). Expression is also observed in motor neurons of the ventral and dorsal nerve cord and several other neuronal commissures throughout the body, and the tail neurons (Fig. 2B,C). The fusion protein is localized throughout the cell body and axonal and dendritic processes of neurons but is usually excluded from the nucleus (Fig. 2AC). Additional tissues that consistently express AKT-1/ GFP include neurons and muscle cells of the pharynx, the rectal gland cells, and the spermatheca (Fig. 2A,C,D). AKT-1/GFP expression was observed more variably in a variety of cell types including hypodermis, intestine, muscle, some of the P-cell descendants that form the vulva, and in the excretory canal.

Consistent with redundant roles of akt- 1 and akt-2, an AKT-2/GFP full-length protein fusion gene is expressed at the same times as AKT-1/GFP and in the same tissues that express AKT-1/GFP al though AKT-2/GFP seems to be less abundant (Fig. 2E). These expression patterns are consistent with AKT-1 and AKT-2 functioning either in secretory neurons to regulate dauer arrest and metabolic shift or in the target tissues that are remodeled during dauer formation, such as the phayrnx, hypodermis, and intestine (Riddle and Albert 1997).

\section{Discussion}

The C. elegans Akt/PKB homologs AKT-1 and AKT-2 function to antagonize the DAF-16 transcription factor

Table 4. Effects of akt-1(mgl44) on life span extension of age-1(mg44)

\begin{tabular}{lcccc}
\hline & \multicolumn{3}{c}{ Life span (days) } \\
\cline { 2 - 3 } Strain & mean & maximum & $N^{a}$ \\
\hline Wild type & 12 & 16 & 28 \\
sqt-1(sc13) age-1(mg44) & 18 & 36 & 20 \\
daf-16(m27); sqt-1(sc13) agel(mg44) $^{\mathrm{c}}$ & 14 & 16 & 32 \\
sqt-1(sc13) age-1(mg44); akt-1 (mg144) $^{c}$ & 22 & 38 & 36
\end{tabular}

All mean life spans are significantly different $(P \leq 0.02$; see $M$ aterials and $M$ ethods) from each other except for age-1(mg44) vs. age-1(mg44); akt-1(mg144).

a(N) Total number of animals scored. N umbers are from one representative experiment, which has been performed at least one other time and gave similar results.

'T hese animals are the homozygous age-1 progeny of age-1/ bal ancer hermaphrodites.

'These animals are the homozygous age-1 progeny of age-1 hermaphrodites. 

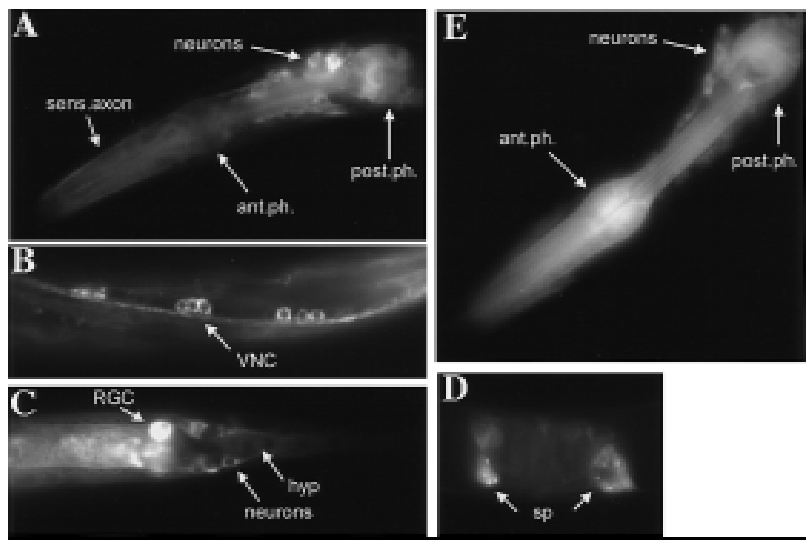

Figure 2. $A K T-1 / G F P$ and $A K T-2 / G F P$ expression. (A-D) AKT-1/GFP expression; (E) AKT-2/GFP expression. (A) AKT-1/ GFP expression in the head of an L2 animal. Expression in the anterior and posterior bulb of the pharynx (ant.ph. and post.ph.) is shown; expression in the isthmus of the pharynx is also observed. $M$ any neurons in the head express AKT-1/GFP; expression in the neuronal nuclei is not visible. Also, expression can be seen in sensory axons (sens.axon) that proceed to the nose of the animal. (B) AKT-1/GFP expression in the ventral nerve cord (VNC) of an L1 animal (anterior is to the left). Both cell bodies (nuclei do not appear to express AKT-1/GFP) and axons of the VNC are clearly visible. Animal appears twisted because of coinjection with the rol-6 marker. (C) AKT-1/GFP expression in the tail of an $\mathrm{LI}$ animal. The rectal gland cell (RGC), neurons of the tail with axons, and hypodermal cells (hyp) all clearly express AKT-1/GFP. AKT-1/GFP expression is not visible in the nuclei. (D) AKT-1/GFP expression in the spermatheca (sp) of an adult animal. (E) AKT-2/GFP expression in the head of an L4 animal. Expression in the anterior and posterior bulb of the pharynx (ant.ph. and post.ph.) is indicated; expression in the isthmus of the pharynx is also visible. Also shown is AKT-2/ GFP expression in many neurons in the head; the nuclei appear to be excluded from AKT-2/GFP expression. AKT-2/GFP expression in the $\mathrm{VNC}$, tail, and spermatheca was similar to that observed for AKT-1/GFP.

and repress the metabolic shift and growth arrest associated with the dauer stage. Both AKT-1 and AKT-2 transduce DAF-2 signals because both gene activities must be decreased to cause dauer arrest. Because a null mutation in daf-16 bypasses the normal requirement for C. el egans Akt/PKB signaling, the primary function of AKT-1 and AKT-2 is to antagonize DAF-16. Interestingly, DAF-16 contains four consensus sites for phosphorylation by Akt/PKB (Alessi et al. 1996b) and three of these sites are conserved in the human DAF-16 homologs FKHRL1, FKHR, and AFX (Fig. 3C). AKT-1 and AKT-2 in C. elegans (and Akt/PKB in mammals) may exert their negative regulatory effect by directly phosphorylating DAF-16 (and FKHRL1, FKHR, and AFX in mammals) and altering its transcriptional regulatory function.

The activating mutation akt- 1 ( $\mathrm{mgl} 144)$ as well as overexpression of akt-1(+) bypasses the normal requirement for AGE-1 PI3K signal ing in the DAF-2 insulin receptorlike signal transduction pathway. These results demonstrate that $C$. elegans Akt/PKB gene activity is not strictly dependent on upstream age-1 activity if Akt/ PKB activity is increased. In the al most complete C. elegans genome sequence, AGE-1 is the only PI3K homolog of the type known to generate 3-phosphoinositides (C.A. Wolkow and G. Ruvkun, pers. comm.). If AGE-1 is the only protein able to generate 3-phosphoinositides in C. elegans, our results suggest that although normal AKT-1 signaling is dependent on 3-phosphoinositides, AKT-1 can become activated in their absence if gene dosage is increased or the mg144 mutation is introduced.

Importantly, either activated akt-1 or higher akt-1(+) gene dosage does not efficiently suppress mutations in the DAF-2 insulin receptor suggesting that age-1 and akt-1 constitute one major signaling pathway from DAF-2 and that other, as yet unidentified genes, constitute one or more parallel pathways. These pathways most likely converge on the DAF-16 Fork head transcription factor and negatively regulate its activity, as lossof-function mutations in daf-16 completely suppress both daf-2 and age-1 mutations (Gottlieb and Ruvkun 1994; Larsen et al. 1995), as well as inactivation of akt-1 and akt-2 signaling.

Although AKT -1 and AKT-2 appear to function redundantly in transduction of DAF-2/AGE-1 signals, increased akt-1 gene dosage is a much more potent suppressor of age-1 null mutations than increased akt-2 gene dosage. A major distinction between AKT-1 and AKT-2 is that AKT-1 bears two phosphorylation sites (corresponding to Thr-308 and Ser-473 in human Akt/ $\mathrm{PKB} \alpha$ ) (Fig. 1D) that are necessary for activation of A kt/ PKB by upstream growth factor inputs (Alessi et al. 1996a), whereas A KT-2 only has the Thr-308 phosphorylation site (Fig. 1D). In mammals, Akt/PKB is phosphorylated at Thr-308 by PDK1 and at Ser-473 by the as yet unpurified PDK2 (Alessi et al. 1997; Stokoe et al. 1997). Therefore AKT-1 may couple to a PDK2-like kinase whereas AKT-2 cannot do so. AKT-1 and AKT-2 may also differ in other kinase inputs or in their substrates. Interestingly, at lower temperatures, the akt-2(t) transgene can supply sufficient Akt/PKB activity to weakly suppress the dauer arrest caused by age-1(mg44) (S. Paradis and G. Ruvkun, unpubl.). Temperature is a major modul ator of dauer arrest (Riddleand Albert 1997). The penetrance of dauer arrest in most dauer constitutive mutants is increased at high temperatures (Riddle and Albert 1997), suggesting that some signals in the pathway are enhanced at low temperature. Therefore at low temperatures perhaps PDK1 signal ing to AKT-1 and AKT-2 or signaling in pathways paral lel to AGE-1/AKT$1 /$ AKT -2 are enhanced, now al lowing increased akt-2(+) gene dosage to weakly bypass the normal requirement for AGE-1 PI3K signaling.

Insulin-like and transforming growth factor- $\beta$ (TGF- $\beta$ ) neuroendocrine signals regulate whether animals arrest at the dauer stage or grow to reproductive adults (Kimura et al. 1997; Riddle and Albert 1997). The TGF- $\beta$-like molecule DAF-7 is a probable neuroendocrine signal-it is expressed in the sensory neuron ASI that represses dauer arrest (Bargmann and Horvitz 1991) and its expression is regulated by dauer-inducing pheromone (Ren et 
A Low Pheromone

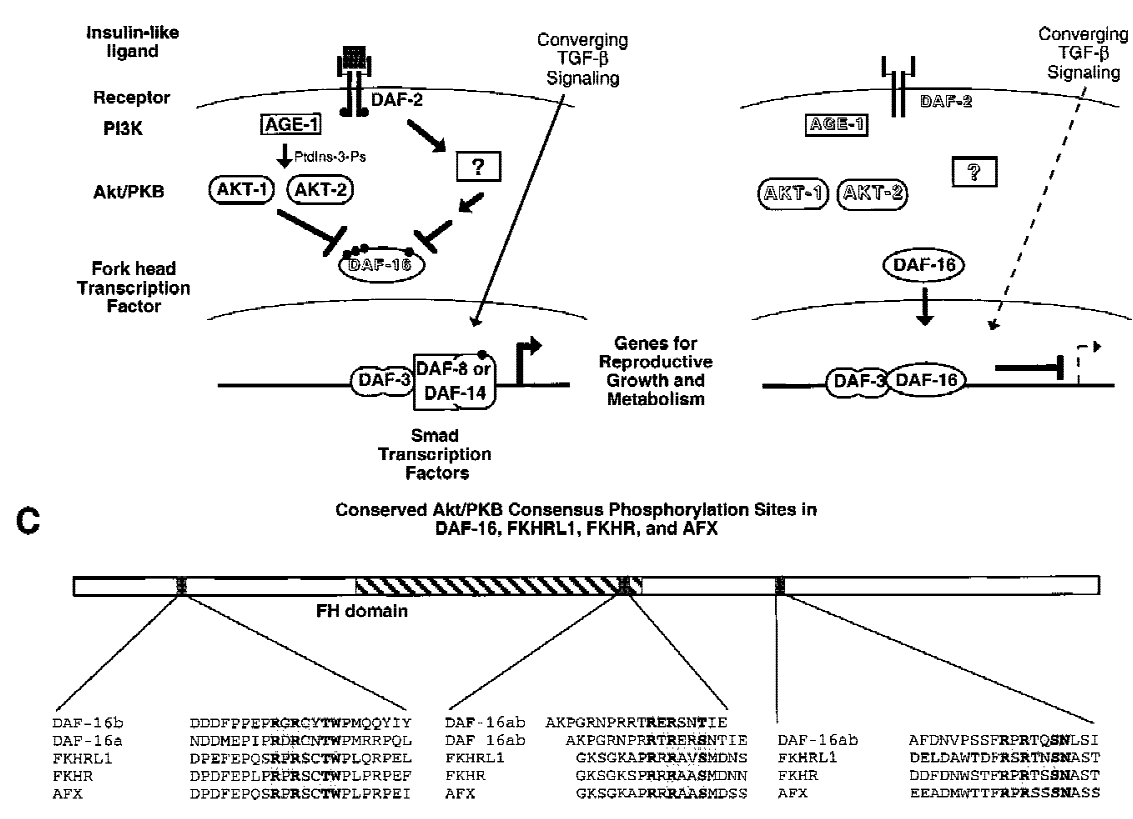

Figure 3. M odel for regulation of dauer formation by AGE-1 PI3K activation of AKT1/AKT-2. (A) N ormal growth occurs in conditions of low pheromone as a result of DAF-2 insulin receptor-like signaling and converging TGF- $\beta$ signaling; DAF-16 is possibly inactivated by phosphorylation in these growth conditions. (See text for details.) (B) Dauer arrest occurs in conditions of high pheromone that cause lack of DAF-2 insulin receptor-like signaling and converging TGF- $\beta$ signaling; DAF-16 may repress transcription in these conditions. (See text for details.) (C) Location and sequence context of consensus Akt/PKB phosphorylation sites in DAF-16 and the human homologs FKHRL1, FKHR, and AFX. daf-16 is differentially spliced to produce two gene products (DAF-16a and DAF-16b) that differ in the amino-terminal one-third of the protein but are identical (DAF-16ab) for the remainder of the protein. The consensus Akt/PKB phosphorylation site, RXRXXS/ THyd (Alessi et al. 1996b), is boxed in gray and the amino acid residues identical in that site in all proteins are in boldface type. Other amino acid residues flanking these sites are also identical or show conservative substitutions in all proteins but are not in boldface type. The sites are located in the same relative regions of each protein, near the amino terminus, at the carboxy-terminal region of the Fork head DNA-binding domain (but downstream of the DNA recognition helix) and downstream of the Fork head domain. N ote that two adjacent Akt/PKB consensus sites occur within the Fork head domain of DAF-16 and are shown aligned with a single $A$ kt/PKB consensus site in FKHRL1, etc.

al. 1996; Schackwitz et al. 1996). Although the insulinlike ligand for the DAF-2 insulin-like receptor has not yet been identified, it may also be produced by secretory neurons and regulated by pheromone. Precedence from biochemical analysis predicts that DAF-2, AGE-1, AKT$1 / A K T-2$, and DAF-16 function in the same cells. It is not yet clear whether the DAF-2 signal ing pathway acts in the target tissues that are remodel ed in dauer larvae, such as the pharynx, hypodermis, and intestine, or in other signaling cells that in turn control target tissues. The broad expression pattern of akt- 1 and akt- 2 includes the nervous system, pharynx, and hypodermis. This expression pattern is consistent with a role for these genes either in sensory neurons that signal to repress dauer arrest or in the target tissues that receive the dauer repressing signal. The expression patterns of daf- 2 and age-1 have not been reported; daf-16 is widely expressed (Ogg et al. 1997) as are daf-3 and daf-4, two genes that comprise the DAF-7 TGF- $\beta$ signal reception pathway (Patterson et al. 1997). M osaic or tissue-specific expression analysis will be required to demonstrate in which cell types the DAF-2 insulin-like and DAF-1/DAF-4 TGF- $\beta$ signal transduction pathways act.

The role of AKT-1 and AKT-2 in regulating the metabolic shift and developmental arrest associated with dauer formation suggests the following model (Fig. 3). Under normal growth conditions (Fig. 3A), an insulinlike molecule binds to the DAF-2 insulin receptor kinase inducing autophosphorylation and recruitment of AGE-1 PI3K. A parallel pathway (or pathways) from the DAF-2 insulin receptor-like protein is also activated. The AKT-1 and AKT - 2 kinases, as well as molecules from the parallel pathway, negatively regulate DAF-16 activity, possibly via phosphorylation. Phosphorylated DAF-16 could be inactive, function to activate genes required for reproductive growth and metabolism, or repress genes required for dauer arrest and energy storage. Other signaling molecules that are activated by DAF- 2 must also converge downstream of AGE-1 (e.g., on DAF-16 or AKT 1/AKT-2) for proper regulation of metabolism and life span. The dauer arrest induced by loss of AGE-1 PI3K or AKT-1/AKT-2 activity implies that the loss of only one of these inputs to DAF-16 is sufficient to cause dauer arrest. Under dauer-inducing conditions, DAF-2, AGE-1, AKT-1/AKT-2, and other signaling pathways from DAF-2 are inactive and therefore DAF-16 is active, presumably because it is under-phosphorylated (Fig. 3B). Active DAF-16 either represses genes required for reproductive growth and metabolism or activates genes necessary for dauer arrest and energy storage.

The DAF-16 Fork head protein has been suggested to interact with the DAF-3, DAF-8, or DAF-14 Smad proteins to integrate converging TGF- $\beta$-like neuroendocrine signals with insulin-like signals (Ogg et al. 1997; Patterson et al. 1997). DAF-16 may form a complex with the DAF-3 Smad protein under dauer-inducing conditions to regulate these downstream genes (Ogg et al. 1997) and AKT-1/AKT-2 phosphorylation of DAF-16 may inhibit the formation of a Smad/Fork head complex during reproductive devel opment. 
Akt/PKB has been implicated in mammalian insulin receptor signaling that localizes gl ucose transporters to the plasma membrane (Kohn et al. 1996) and has been shown to regulate glycogen synthesis via direct phosphorylation of GSK 3 (Cross et al. 1995); two events that are not transcriptional. Whereas there also may be such Akt/PKB outputs in C. elegans, the DAF-16 Fork head transcription factor represents the major output of DAF2/AGE-1/AKT-1/AKT-2 insulin receptor-like signaling (Ogg et al. 1997). Similarly Akt/PKB action in the insuIin/IGF-I anti-apoptotic pathway (Dudek et al. 1997; Kauffmann-Zeh et al. 1997; Kulik et al. 1997) may also converge on transcription factors related to DAF-16.

Our model, based on genetic evidence that Akt/PKB couples insulin receptor-like signaling to transcriptional output via the DAF-16 Fork head transcription factor in C. elegans, predicts that Akt/PKB will have transcripti onal outputs in insulin-likesignaling across phylogeny. Human homol ogs of DAF-16 may be the pertinent downsteam effectors of insulin signaling (Ogg et al. 1997). Two of the consensus Akt/PKB sites conserved in DAF16 and its human homologs are located outside of the Fork head DNA-binding domain, and two sites are located in the highly basic W2 region of the Fork head domain that has been shown to mediate DN A phosphate backbone contacts (Clark et al. 1993) and possibly nuclear localization (Qian and Costa 1995) (Fig. 3C). Insulin-stimulated Akt/PKB phosphorylation of the W2 sites may affect DNA nuclear localization or binding, whereas the other conserved sites may affect transactivation. A recent report shows that Akt/PKB mediates insulin-dependent repression of the insulin-like growth factor binding protein-1 (IGFBP-1) gene in HepG2 cells via a conserved insulin response sequence (CAAAAC/ TAA) (Cichy et al. 1998). Interestingly, DAF-16 binds to this same insul in response sequence in vitro ( $\mathrm{N}$. N asrin, S. Ogg, G. Ruvkun, and M. Alexander-Bridges, pers. comm.). We propose that Akt/PKB mediates its transcriptional effects on insulin-responsive genes such as IGFBP-1 via the human homologs of DAF-16: FKHRL1, FKHR, and AFX.

\section{Materials and methods}

\section{akt-1(mg144) isolation and mapping}

A parent strain carrying the sqt-1(sc13) age-1(mg44) chromosome balanced with the crossover suppressor chromosome $\mathrm{mnC} 1$ was mutagenized with ethylmethanesulfonate and more than 3800 haploid genomes screened in the $F_{2}$ or $F_{3}$ generation for zygotic or maternal effect suppressors of age-1(mg44) by scoring for animals that did not arrest at the dauer stage. Ten independent suppressor loci emerged from the screen, one of which is akt-1(mgl44). M apping was performed by crossing sqt1 (sc13) age 1 ( $\mathrm{mg} 44) /+$; akt- 1 (mgl44)/ + males to the polymorphic strain RW7000 hermaphrodites. sqt-1(sc13) age-1(mg44); akt-1(mg144) animals were isolated and assayed by PCR for various STS polymorphisms on each chromosome as described (Williams 1995). Of nine animals, one had the chromosome $V$ marker bP1, whereas markers from other chromosomes assorted independently; we therefore conclude that mgl44 is linked to chromosome V. An additional 30 sqt-1(sc13) age-
1 (mg44); akt-1(mg144) animals from this cross were assayed for the chromosome $V$ markers stP192, bP1, stP6, and stP18 (Fig. 1A). Of 30 animals, 2 carried both stP6 and stP18. Because none carried bP1, the two-factor map distance between bP1 and mg144 is $1 / 39$ recombinants, or 1.3 m.u. Additionally, this mapping experiment places mgl44 left of stP6 and either left of bP1 or close to bP1 on the right.

\section{Allele sequencing}

Genomic DNA from akt-1(mgl44) and age-1(mg109) strains was PCR-amplified and directly sequenced. Sequencing of the age-1(mgl09) strain revealed that the previous report of this mutation is incorrect (M orris et al. 1996). The missense mutation in age-1(mg109) changes a conserved serine to an asparagine in the kinase domain (Ser-826-Asn, VLGSAKRP).

\section{cDNA characterization}

akt-la gene structure was confirmed by sequencing of cDN As (yk551d10, yk450a7 provided by $\mathrm{Y}$. Kohara ( $\mathrm{N}$ ational Institute of Genetics, Mishima, Japan) and CEESY 35 provided by The Institute for Genomic Research (Rockville, MD) and by 5' RACE (GIBCO) using a gene-specific primer to exon 6 for reverse transcription. akt-1b gene structure was confirmed by sequencing of a cDN A (yk131h3 provided by Y. Kohara) that confirms exon 5 through the 3' UTR only and 5' RACE (GIBCO) with a gene-specific primer to exon 7 for reverse transcription. The akt-la and akt-lb messages analyzed by 5' RACE were trans-spliced with an SL1 leader sequence 49 bp upstream of the first methionine. akt-2 gene structure was confirmed by sequencing of a cDNA (yk232g7 provided by $Y$. Kohara) and 5' RACE (GIBCO) using a gene-specific primer to exon 4 for reverse transcription. The akt- 2 message analyzed by $5^{\prime}$ RACE was trans-spliced with a SL1 leader sequence $7 \mathrm{bp}$ upstream of the first methionine.

\section{Scoring of akt-1(mgl44) effects on dauer constitutive} mutations

Gravid adults were al lowed to lay eggs for $3 \mathrm{hr}$ at $25^{\circ} \mathrm{C}$. Progeny were scored at $48 \mathrm{hr}$ post-egg lay for dead eggs, between $50-62 \mathrm{hr}$ post-egg lay for all other categories, and some strains were rescored at 72 or $96 \mathrm{hr}$ post-egg lay. For all assays performed for this study, the following scoring categories were used. Scoring with a dissecting microscope, "partial dauer" refers to animals that were arrested and had a dark intestine like age- 1 or daf- 2 dauers but were not as fully constricted as age-1 or daf- 2 dauers; or animals that were arrested and constricted like age-1 or daf-2 dauers but did not have as dark an intestine as age-1 or daf-2 dauers. "Other" refers to animals that could not be classified as dauer, etc. because the animal was young, was male, had grossly aberrant morphol ogy, or was dead. Sometimes this class was not determined because the $F_{2}$ generation was growing on the plate when the plate was scored.

Construction of akt-1 and akt- 2 transgenic lines and scoring of akt- 1 and akt-2 transgene effects on dauer constitutive mutations

A 7.3-kb PCR product of genomic DNA from the akt-1(+) or akt-1(mgl44) genomic region containing $3.2 \mathrm{~kb}$ of $5^{\prime}$ upstream regulatory sequence (the next gene on the cosmid, transcribed in the same direction, ends $\sim 5 \mathrm{~kb} 5^{\prime}$ to akt- 1 ), $3.5 \mathrm{~kb}$ of coding sequencing containing introns and exons, and $0.6 \mathrm{~kb}$ of akt-1 $3^{\prime}$ UTR was purified using QIAquick (Qiagen) and injected at 10 $\mathrm{ng} / \mathrm{ml}$ with ttx-3::GFP at $50 \mathrm{ng} / \mu \mathrm{l}$ (pPD95.75-C40H5-GFP, O. Hobert, MGH and Harvard Medical School) as a coinjection 
marker (M ello et al. 1991). akt-1(KD) was constructed and injected in the same manner except PCR primers were used to introduce the $\mathrm{K} \rightarrow \mathrm{M}$ mutation. A 5.9-kb PCR product of genomic DN A from the akt-2(+) genomic region comprising $2.1 \mathrm{~kb}$ of $5^{\prime}$ upstream regulatory sequence (because the cosmid was in shotgun sequencing status at the time so the location of a $5^{\prime}$ upstream gene could not be determined, a conservative amount of upstream regulatory sequence was used), $3.1 \mathrm{~kb}$ of coding sequence including introns and exons, and $0.7 \mathrm{~kb}$ of akt- $23^{\prime}$ UTR was purified and injected as for akt-1 constructs. Once transgenic lines were established in wild type, they were crossed into either age-1(mg44) or daf-2(e1370) mutant backgrounds. To score the arrays in a wild type background, a 3-hr egg lay was performed at $25^{\circ} \mathrm{C}$. Transgenic progeny from the egg lay were scored $\sim 48 \mathrm{hr}$ post-egg lay as dauer or nondauer (L4 larvae, gravid adult, or sterile adult); some additional progeny were scored at $\sim 72 \mathrm{hr}$ post-egg lay. Initially, six independent akt-1(mg144) transgenes and four independent akt- $1(+)$ transgenes were crossed into age-1(mg44). Five of six akt-1(mgl44) transgenes were able to partial ly suppress age-1(mg44), whereas one of six did not. Four of four akt-1(+) trangenes partially suppressed age-1(mg44). To collect the data in Table 3, two independent akt-1(mgl44) transgenes and two independent akt-1(+) transgenes in an age-1(mg44) background were used to perform a 5-hr egg lay at $25^{\circ} \mathrm{C}$. Transgenic progeny from the egg lay were scored $72 \mathrm{hr}$ post egg lay as dauer or nondauer (gravid or sterile adult). To score daf-2(e1370) suppression by the various transgenes gravid adults were shifted to $25^{\circ} \mathrm{C}$ and allowed to lay a brood. Progeny were scored approximately $48 \mathrm{hr}$ or $72 \mathrm{hr}$ postshift for akt-1(KD) and akt-2(+) transgenic animals and $\sim 96 \mathrm{hr}$ postshift for akt-1(+) and akt-1(mgl44) transgenic animals as dauer or non-dauer (gravid or sterile adult).

\section{RNAi}

The akt-1 coding region was amplified from CEESY 35 (The Institute for Genomic Research) by PCR (primers CM O24 5'-TTGTAAAACGACGGCCAG and CMO25 5'-CATGATTACGCCAAGCTC). The akt-2 coding region was amplified by PCR from yk232g7 (Y. Kohara) using CM O24 and CM O25. RN A was transcribed using MEGAscript T3 and T 7 kit (Ambion). Singlestranded RNAs were combined before injection and stored on ice during injection. Approximately $5 \mu \mathrm{g} / \mu \mathrm{l}$ double-stranded RN A for single-gene injections and $\sim 2.5 \mu \mathrm{g} / \mu \mathrm{l}$ double-stranded RNA per gene for double-gene injections was injected into the gut of L4 hermaphrodites. Animals were all owed to recover for $24 \mathrm{hr}$ at $20^{\circ} \mathrm{C}$ then moved to fresh plates and al lowed to lay eggs for $24 \mathrm{hr}$ at $25^{\circ} \mathrm{C}$. Broods were scored for dead eggs day 1 postegg lay, and for dauers or L4 larvae and adults day 2 post-egg lay.

\section{Life span assays}

A nimals were synchronized by performing an egg lay at $25^{\circ} \mathrm{C}$ for $3 \mathrm{hr}$. Four days after egg lay, the animals were transferred to new plates (five animals/plate) and the animals were scored and moved away from their progeny every two days while the animals were laying their brood; animals were scored every 2-3 days subsequently and moved periodically to keep growth conditions mold free. Animals were scored as dead if they failed to respond to a gentle tap on the head and tail with a platinum wire. Life span is defined as day of egg lay $(t=0)$ to day the worm was scored as dead. A t-test was performed to compare mean life spans of each strain pairwise.

\section{akt-1 and akt-2 expression}

The AKT-1/GFP translational fusion was constructed as follows. A 6.7-kb PCR product of genomic DN A from akt-1 geno- mic region comprising $3.2 \mathrm{~kb}$ of $5^{\prime}$ upstream regulatory region and $3.5 \mathrm{~kb}$ of coding region including exons and introns was fused by PCR in-frame to a GFP with unc-54 3' UTR PCR product from pPD95.75 (A. Fire, Carnegie Institute of Washington, Baltimore, MD). This $5^{\prime}$ upstream regulatory region is the same as that used for the age-1(mg44) suppression experiment (see text). PCR products were purified using QIAquick (Qiagen) and injected with rol-6 (pRF4, $100 \mathrm{ng} / \mu \mathrm{l}$ ) as the coinjection marker (Mello et al. 1991). The AKT-2/GFP translational fusion was constructed similarly using a $5.2-\mathrm{kb}$ PCR product from the akt-2 genomic region comprising $2.1 \mathrm{~kb}$ of $5^{\prime}$ upstream regulatory region and $3.1 \mathrm{~kb}$ of coding region, including exons and introns. This $5^{\prime}$ upstream regulatory region is the same as that used for the age-1(mg44) suppression experiment (see text).

\section{Acknowledgments}

We thank Y. Liu for expert technical assistance; C.A. Wolkow, N. N asrin, S. Ogg, and M. Alexander-Bridges for sharing results prior to publication; O. Hobert, B. Reinhart, G. Patterson, and J. Sze for assistance with cell identifications; $Y$. Kohara and The Institute for Genomic Research for providing CDNAs; C. M ello for advice on the RNAi technique; M. Robinson for statistical anaylsis; and members of the Ruvkun lab for hel pful comments and suggestions and critical reading of the manuscript. Some of the strains were provided by the $C$. el egans Genetics Center, which is supported by the $\mathrm{N}$ ational Center for Research $\mathrm{Re}$ sources. This work was supported by $\mathrm{N}$ ational Institutes of Health grant RO1AG14161.

The publication costs of this article were defrayed in part by payment of page charges. This article must therefore be hereby marked "advertisement" in accordance with 18 USC section 1734 solely to indicate this fact.

\section{References}

Alessi, D.R., M. Andjelkovic, B. Caudwell, P. Cron, N. M orrice, P. Cohen, and B.A. Hemmings. 1996a. Mechanism of activation of protein kinase B by insulin and IGF-1. EMBO J. 15: 6541-6551.

Alessi, D.R., F.B. Caudwell, M. Andjeclkovic, B.A. Hemmings, and P. Cohen. 1996b. M olecular basis for the substrate specificity of protein kinase B; comparison with MAPKAP kinase-1 and p70 S6 kinase. FEBS Lett. 399: 333-338.

Alessi, D.R., S.R. James, C.P. Downes, A.B. Holmes, P.R.J. Gaffney, C.B. Reese, and P. Cohen. 1997. Characterization of a 3-phosphoinositide-dependent protein kinase which phosphorylates and activates protein kinase $\mathrm{B} \alpha$. Curr. Biol. 7: 261-269.

Avruch, J. 1998. Insulin signal transduction through protein kinase cascades. Mol. Cell. Biochem. 182: 31-48.

Bargmann, C.I. and H.R. Horvitz. 1991. Control of larval development by Chemosensory neurons in Caenorhabditis elegans. Science 251: 1243-1246.

Carpenter, C.L. and L.C. Cantley. 1996. Phosphoinositide kinases. Curr. Opin. Cell Biol. 8: 153-158.

Chalfie, M., Y. Tu, G. Euskirchen, W.W. Ward, and D.C. Prasher. 1994. Green fluorescent protein as a marker for gene expression. Science 263: 802-805.

Cichy, S.B., S. Uddin, A. Danilkovich, S. Guo, A. Klippel, and T.G. Unterman. 1998. Protein kinase B/Akt mediates effects of insulin on hepatic insulin-like growth factor-binding protein-1 gene expression through a conserved insulin response sequence. J. Biol. Chem. 273: 6482-6487.

Clark, K.L., E.D. Halay, E. Lai, and S.K. Burley. 1993. Co-crystal structure of the HNF-3/fork head DNA-recognition motif resembles histone H5. Nature 364: 412-420. 
Cross, D.A.E., D.R. Alessi, P. Cohen, M. Andjelkovich, and B.A. Hemmings. 1995. Inhibition of glycogen synthase kinase-3 by insulin mediated by protein kinase B. Nature 378: 785789.

Dorman, J.B., B. Albinder, T. Shroyer, and C. Kenyon. 1995. The age- 1 and daf- 2 genes function in a common pathway to control the lifespan of Caenorhabditis elegans. Genetics 141: 1399-1406.

Dudek, H., S.R. Datta, T.F. Franke, M.J. Birnbaum, R. Y ao, G.M. Cooper, R.A. Segal, D.R. Kaplan, and M.E. Greenberg. 1997. Regulation of neuronal survival by the serine-threonine protein kinase Akt. Science 275: 661-665.

Fire, A., S. Xu, M.K. M ontgomery, S.A. Kostas, S.E. Driver, and C.C. M ello. 1998. Potent and specific genetic interference by double-stranded RNA in Caenorhabditis elegans. Nature 391: 806-811.

Franke, T.F., S.-I. Yang, T.O. Chan, K. Datta, A. Kaziauskas, D.K. Morrison, D.R. Kaplan, and P.N. Tsichlis. 1995. The protein kinase encoded by the Akt proto-oncogene is a target of the PDGF-activated phosphatidylinositol 3-kinase. Cell 81: 727-736.

Franke, T.F., D.R. Kaplan, L.C. Cantley, and A. Toker. 1997. Direct regulation of the Akt proto-oncogene product by phoshatidylinositol-3,4-bisphosphate. Science 275: 665-668.

Frech, M., M. Andjelkovic, E. Ingley, K.K. Reddy, J.R. Falck, and B.A. Hemmings. 1997. High affinity binding of inositol phosphates and phosphoinositides to the pleckstrin homology domain of RAC/protein kinase $B$ and their influence on $\mathrm{ki}$ nase activity. J. Biol. Chem. 272: 8474-8481.

Gottlieb, S. and G. Ruvkun. 1994. daf-2, daf-16, and daf-23: Genetically interacting genes controlling dauer formation in Caenorhabditis el egans. Genetics 137: 107-120.

Hanks, S.K. and T. Hunter. 1995. The eukaryotic protein kinase superfamily. In The protein kinase facts book protein-serine kinases (ed. G. Hardie and S. Hanks), pp. 7-47. Academic Press, San Diego, CA.

Kahn, C.R. 1994. Insulin action, diabetogenes, and the cause of type II diabetes. Diabetes 43: 1066-1084.

Kapeller, R. and L.C. Cantley. 1994. Phosphatidylinositol 3-kinase. BioEssays 16: 565-576.

Kauffmann-Zeh, A., P. Rodriguez-Viciana, E. Ulrich, C. Gilbert, P. Coffer, J. Downward, and G. Evan. 1997. Suppression of C-Myc-induced apoptosis by Ras signalling through $\mathrm{PI}(3) \mathrm{K}$ and PKB. Nature 385: 544-548.

Kenyon, C., J. Chang, E. Gensch, A. Rudner, and R. Tabtlang. 1993. A C. elegans mutant that lives twice as long as wild type. Nature 366: 461-464.

Kimura, K., H.A. Tissenbaum, Y. Liu, and G. Ruvkun. 1997. daf-2, an insulin receptor-like gene that regulates longevity and diapause in Caenorhabditis el egans. Science 277: 942946.

Klass, M. 1983. A method for the isolation of longevity mutants in the nematode $C$. el egans and initial results. Mech. Aging Dev. 22: 279-286.

Klippel, A., W.M. Kavanaugh, D. Pot, and L.T. Williams. 1997. A specific product of phosphatidylinositol 3-kinase directly activates the protein kinase Akt through its pleckstrin homology domain. Mol. Cell. Biol. 17: 338-344.

Kohn, A.D., S.A. Summers, M.J. Birnbaum, and R.A. Roth. 1996. Expression of constitutively active Akt Ser/Thr kinase in 3T 3-L1 adipocytes stimulates gl ucose uptake and glucose transporter 4 translocation. J. Biol. Chem. 271: 3137231378.

Kulik, G., A. Klippel, and M.J. Weber. 1997. Antiapoptotic signalling by the insulin-like growth factor I receptor, phophatidylinositol 3-kinase, and Akt. Mol. Cell. Biol. 17: 15951606.
Larsen, P. L., P. S. Albert, and D. L. Riddle. 1995. Genes that regulate both development and Iongevity in Caenorhabditis elegans. Genetics 139: 1567-1583.

Lin, K., J.B. Dorman, A. Rodan, and C. Kenyon. 1997. daf-16: An HN F-3/forkhead family member that can function to double the life-span of Caenorhabditis elegans. Science 278: 13191322.

M ello, C.C., J.M. Kramer, D. Stinchcomb, and V. Ambros. 1991. Efficient gene transfer in C. elegans: Extrachromosomal maintenance and integration transforming sequences. EMBO J. 10: 3959-5970.

Morris, J.Z., H.A. Tissenbaum, and G. Ruvkun. 1996. A phosphatidylinositol-3-OH kinase family member regulating longevity and diapause in Caenorhaditis elegans. Nature 382: 536-539.

M usacchio, A., T. Gibson, P. Rice, J. Thomson, and M. Saraste. 1993. The PH domain: A common piece in the structural patchwork of singalling proteins. Trends Biochem. Sci. 18: 343-348.

Ogg, S., S. Paradis, S. Gottlieb, G.I. Patterson, L. Lee, H.A. Tissenbaum, and G. Ruvkun. 1997. The Fork head transcription factor DAF-16 transduces insul in-like metabolic and longevity singals in C. el egans. Nature 389: 994-999.

Patterson, G., A. Koweek, A. Wong, Y. Liu, and G. Ruvkun. 1997. The DAF-3 Smad protein antagonizes TGF- $\beta$-related receptor signaling in the Caenorhabditis el egans dauer pathway. Genes \& Dev. 11: 2679-2690.

Qian, X. and R.H. Costa. 1995. Analysis of hepatocyte nuclear factor-3 $\beta$ protein domains required for transcriptional activation and nuclear targeting. Nucleic Acids Res. 23: 11841191.

Ren, P., C.-S. Lim, R. Johnsen, P.S. Albert, D. Pilgrim, and D.L. Riddle. 1996. Control of C. elegans larval development by neuronal expression of a TGF- $\beta$ homolog. Science 274: 1389-1392.

Riddle, D.L. and P.S. Albert. 1997. Genetic and environmental regulation of dauer larva development. In C. elegans II (ed. D. L. Riddle, T. Blumenthal, B.J. Meyer and J.R. Priess), pp. 739-768. Cold Spring Harbor Laboratory Press, Cold Spring Harbor, NY.

Rocheleau, C.E., W.D. Downs, R. Lin, C. Wittmann, Y. Bei Y.-H. Cha, M. Ali, J.R. Priess, and C.C. Mello. 1997. Wnt signaling and an APC-rel ated gene specify endoderm in early C. elegans embryos. Cell 90: 707-716.

Schackwitz, W.S., T. Inoue, and J.H. Thomas. 1996. Chemosensory neurons function in parallel to mediate a pheromone response in C. el egans. Neuron 17: 719-728.

Stokoe, D., L.R. Stephens, T. Copeland, P.R.J. Gaffney, C.B. Reese, G.F. Painter, A.B. Holmes, F. McCormick, and P.T. Hawkins. 1997. Dual role of phosphatidylinositol-3,4,5-trisphosphate in the activation of protein kinase B. Science 277: 567-570.

Toker, A. and L.C. Cantley. 1997. Signalling through the lipid products of phophoinositide-3-OH kinase. Nature 387: 673676.

Williams, B.D. 1995. Genetic mapping with polymorphic sequence-tagged sites. In Caenorhabditis el egans modern biological analysis of an organism (ed. H.F. Epstein and D.C. Shakes), pp. 81-97. Academic Press, San Diego, CA.

Wilson, R., R. Ainscough, K. Anderson, C. Baynes, M. Berks, J. Burton, M. Connell, J. Bonfield, T. Copsey, J. Cooper et al. 1994. 2.2 $\mathrm{M} \mathrm{b}$ of contiguous nucleotide sequence from chromosome III of C. elegans. Nature 368: 32-38.

Zhang, B., M. Gallegos, A. Puoti, E. Durkin, S. Fields, J. Kimble, and M. Wickens. 1997. A conserved RNA-binding protein that regulates sexual fates in the $C$. elegans hermaphrodite germ line. Nature 390: 477-484. 


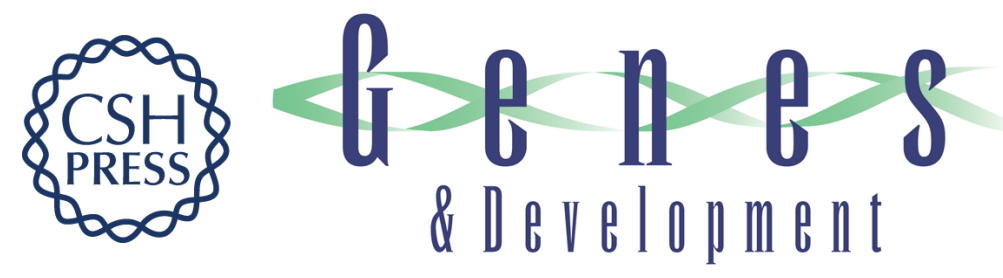

\section{Caenorhabditis elegans Akt/PKB transduces insulin receptor-like signals from AGE-1 PI3 kinase to the DAF-16 transcription factor}

Suzanne Paradis and Gary Ruvkun

Genes Dev. 1998, 12:

Access the most recent version at doi:10.1101/gad.12.16.2488

References

This article cites 40 articles, 18 of which can be accessed free at:

http://genesdev.cshlp.org/content/12/16/2488.full.html\#ref-list-1

License

Email Alerting

Receive free email alerts when new articles cite this article - sign up in the box at the top

Service right corner of the article or click here.

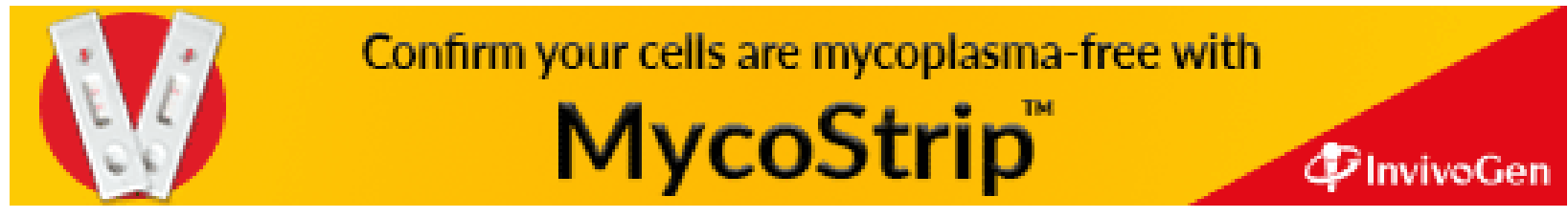

